\title{
Health care in a unique setting: applying emergency medicine at music festivals
}

\author{
This article was published in the following Dove Press journal: \\ Open Access Emergency Medicine \\ 20 September 2012 \\ Number of times this article has been viewed
}

\section{Carl McQueen' \\ Charlotte Davies²}

'The Air Ambulance Service, Coventry, Warwickshire, ${ }^{2}$ Yorkshire Deanery, Yorkshire, UK
Correspondence: Carl McQueen

The Air Ambulance Service, Unit 32, Dakota Road, East Midlands Airport, Castle Donnington, Derbyshire,

DE74 2SA, UK

Tel +44 I6 2372 I333

Email carl_mcqueen@hotmail.com

\begin{abstract}
The last 25 years has seen an explosion in the popularity of outdoor music festivals, especially in the UK. Coupled with this has been the development of the trend for major sporting events that were once confined to stadia to be accompanied by mass gatherings of spectators and fans in "fan parks" and public places. The majority of music festivals and sporting events are considered to be mass gatherings, using the popular definition of more than 1000 people in one place. ${ }^{1}$ Despite the increasing popularity of music festivals and other mass gathering events, there is a lack of scientifically robust data concerning the provision of medical care in these circumstances. Published studies are almost exclusively retrospective reviews or case studies of the care provided at individual events. Prospective studies analyzing the role of medical professionals and the quality of care provided at mass gathering events are extremely rare. This literature review aims to summarize the current literature and provide an opportunity to identify new and exciting avenues for research into this unique field.
\end{abstract}

Keywords: emergency medicine, mass gatherings, festivals, training, governance

\section{Introduction}

The last 25 years has seen an explosion in the popularity of outdoor music festivals, especially in the UK. Coupled with this has been the development of the trend for major sporting events that were once confined to stadia to be accompanied by mass gatherings of spectators and fans in "fan parks" and public places. The majority of music festivals and sporting events are considered to be mass gatherings, using the popular definition of more than 1000 people in one place. ${ }^{1}$

Despite the increasing popularity of music festivals and other mass gathering events, there is a lack of scientifically robust data concerning the provision of medical care in these circumstances. Published studies are almost exclusively retrospective reviews or case studies of the care provided at individual events. Prospective studies analyzing the role of medical professionals and the quality of care provided at mass gathering events are extremely rare. This is probably not unsurprising given the range of statutory, voluntary, and commercial agencies involved in providing medical cover at such events. The majority of the evidence available for the provision of care at events such as music festivals comes from North America and Western Europe, despite the increase in their popularity being a worldwide phenomenon.

Medical provision at music festivals in the UK is regulated by "The purple guide" which was last updated in $1999 .{ }^{2}$ The guide states that the event organizer should aim to reduce the impact of the event on the local National Health Service (NHS). The guide is currently being updated by the events industry forum. ${ }^{3}$ 
Despite its relatively poor quality, the current data available do provide a valuable insight into the scope of practice of medical practitioners at music festivals and other mass gathering events. This literature review aims to summarize the current literature and provide an opportunity to identify new and exciting avenues for research into this unique field.

\section{The popularity of music festivals}

At the time of writing, more than 100 music festivals are scheduled for the summer months in the UK (May-September) alone. Events such as the Glastonbury music festival have a worldwide reputation and are often now seen as a right of passage for many young people in the UK. Equally however, many promoters are offering events specifically tailored to the needs of families and, in the age of austerity, those on a budget. An entire music festival industry has mushroomed in recent years, and with it has developed a wide variety of voluntary and commercial enterprises dedicated to the provision of medical care at events.

In order to understand the role that medical professionals can play at music festivals, one must review the available evidence regarding the range of medical conditions that are encountered and the overall workload at such events.

\section{The workload at music festivals and mass gatherings}

The proportion of the total population of festival goers that access medical care at events is consistently described in the literature as low, ranging from $<0.01 \%$ to $2 \%$ of total patrons at the event. ${ }^{4-9}$ Interactions with medical staff for very simple interventions such as the distribution of sunscreen and simple dressings may be underestimated due to nonrecording of such interventions. ${ }^{10,11}$ Retrospective reviews of the care provided at music festivals consistently identify that the majority of interactions are for relatively simple injuries and complaints. ${ }^{4,10,12-17}$ Smaller numbers of patients require active treatment at the scene or transfer to hospital. ${ }^{13}$ Medical emergencies, requiring specialist resuscitative care, are extremely rare at music events $(0.01 \%-0.04 \%$ of cases $) .{ }^{18}$

The heterogenous pattern of medical attendances at music festivals described in the literature is unsurprising given the population that generally attend these events. Most of the events described in the literature show that the population of patients seen at events are young adults. Evidence from the US has shown that festival goers are less likely to utilize ambulance services than the baseline population in that area. ${ }^{19}$ Given the possibility for the misuse of drugs and alcohol at such events and the potential for accidents or civil disobedience, there is always the potential for the requirement of advanced levels of care. Indeed the type of event has been shown to influence the number of patrons accessing medical care as have other variables including the weather and the day of the week that the event is held on. ${ }^{18,20,21}$

It is also notable that although the "average" festival goer will be a young adult in their late teens/early twenties, significant numbers of attendees at outdoor music events may be children, or middle aged or older. A recent study has highlighted the unexpected number of children seen at a large music festival in the UK. ${ }^{22}$ The difficulty of accurately assessing the age range of attendees at music festivals is due to the lack of reliable data on those who attend but do not seek medical attention. It seems prudent therefore when planning the medical provision for a major event such as a music festival to ensure that medical practitioners have the appropriate training and experience to assess and treat patients of all ages. As the popularity of music festivals increases and the range of events diversifies to attract more families and those that are middle aged, a change in the demographics of festival goers may be observed.

The provision of services provided by organizations offering medical care at music festivals varies. Some voluntary organizations may only be able to provide staff trained in simple first aid techniques. More sophisticated, often commercial, organizations provide a multitude of resources including paramedics, nurses, doctors, private ambulances, and mobile treatment units. Some festivals in the UK even have onsite GP surgeries and pharmacies for patients to access during the event.

With such variations in the staffing and resource allocation between different music festivals, it is important that comparable quality outcome measures are identified for the care provided at events. Equally, the skills and training of individuals deployed in medical care roles at music festivals require scrutiny to ensure that an assessment of the care interventions provided at events can be performed.

\section{Care provision at music festivals}

A variety of health care professional roles and team structures at music festivals have been described in the literature. Work completed in this area however, is limited to case studies and reports from single events across a range of countries. Conclusions derived from such studies therefore may not be transferable between different events and across international boundaries. Nevertheless, paramedics and nursing staff have been demonstrated to have the appropriate skills and experience to provide clinical care at events leading some to 
conclude that the inclusion of staff in these roles negates the need for doctors at music festivals. ${ }^{11-23}$ Given the extremely rare incidence of emergencies that would require extended skill levels at events, this conclusion would not appear unreasonable. Other authors however have documented that emergency medicine residents in the US have been effectively deployed at major events. ${ }^{24}$

The heterogenicity of music festivals does not lend itself to the identification of the optimal framework for the skills and resource allocation appropriate at such events. Some articles have highlighted the success of employing a model that essentially transfers an emergency department model to music festivals, with resources to manage an extremely wide range of medical conditions. ${ }^{17}$ Little is documented, however, about the appropriate level of training needed for medical staff employed at music festivals or the standards of clinical governance required to underpin their clinical practice.

In the UK, the purple guide states that doctors must have an awareness of local major incident plans, and "experience" within the last 2 years, of dealing with emergencies in the pre-hospital or emergency department setting. ${ }^{2}$ Opportunities do exist in the UK to complete training courses in preparation for deployment at mass gatherings and music festivals but such courses are often locally delivered and sometimes specific to certain sites or events. The purple guide cites the completion of the Pre-hospital Emergency Care Course (PHEC) as a "minimum requirement" for training for mass gathering events. It is notable, however, that the PHEC course focuses on the management of major traumatic injuries and medical emergencies in the pre-hospital environment, both of which have been shown to occur rarely at music festivals. Training structures in other countries are not described in the literature.

The question of whether specialist training is required for staff to prepare them to work at events such as music festivals has not yet been addressed.

The requirements of most patients at music festivals are likely to be extremely simple and effectively managed onsite. It is difficult therefore to identify many clear markers of the quality of medical cover at music festivals. One often quoted marker is the incidence of patients transported off site to local emergency departments. ${ }^{4-6,13,15,25}$ Effective medical cover at events such as music festivals is often seen as that which is able to reduce the number of patients utilizing local emergency departments or other statutory agencies. Not only does this reduce the burden on local hospitals, it also has advantages in that it reduces the numbers of clinical personnel needing to leave the site to supervise transfers and is also more convenient for festival patrons. ${ }^{26}$ Some music festivals have effectively employed portable digital radiography onsite to aid in the diagnosis of suspected limb fractures. Coupled with this are facilities onsite for application of plaster casts and frameworks for patient follow-up onsite if required. Such an approach is clearly very skills intensive and may prove costly and may not be suitable for every event. ${ }^{26}$

Measures such as transfer rate to hospital can be used to assess the effectiveness of the medical cover at music festivals but they do not give a detailed insight into the quality of medical care that is provided at the scene. Most of the medical care, however, will be relatively simple; critical events, requiring an advanced level of care, are extremely rare. There are no studies that compare the incidence of major illness or injury between different events, or the range of skills and interventions performed onsite. With the provision of medical care at events such as music festivals being managed by such a wide variety of different agencies, as seen in the US and Western Europe, it is unlikely that detailed studies of this nature will ever be performed. In future, data may need to be drawn from countries where statutory agencies such as ambulance services or local authorities are the primary organizations delivering care at large events. It may be that as music festivals become more popular across the globe, opportunities to conduct this type of research will exist in other countries.

\section{Clinical governance and equipment at events}

There is little regulation and assessment of the standards of clinical governance provided at mass gatherings and music festivals. Concerns have been raised about the overall standard of clinical documentation and data relevant to patient care including vital signs, interventions, and patient disposition. ${ }^{11}$ There are currently no agreed standards for documentation and clinical audit between events in the UK.

The purple guide lists a minimum set of requirements for staffing at first aid and medical centers at events in the UK but offers no further advice on the range of medical kits that is required. ${ }^{2}$ Questions relating to medical kits, and equipment, and the governance and training structures underpinning their use, are often addressed locally.

Guidelines for Australian events are equally vague, listing medical "issues to be considered" including funding, skills, supply, and resupply of medical equipment, and drug storage. The guidelines suggest that "suitable medical facilities" should be onsite, with little clarification of the range of equipment that is required. ${ }^{27}$ 


\section{Planning for care needs at music festivals}

The difficulties in planning medical cover at events such as music festivals are clear. The scope of medical needs at events means that careful prediction is required of patient numbers and the range of conditions and injuries that may be encountered. Evidence shows that the number of patrons at an event however, does not necessarily correlate with the incidence of attendance for medical care. ${ }^{19}$ Medical requirements can also be influenced by factors such as the weather and the type of event that is planned and the clientele that are attracted to such festivals. ${ }^{20,21}$

Plans to cover every event with skills and equipment to manage all possible eventualities may not represent appropriate utilization and resources may prove costly. Much of the information required to plan for music festivals is gleaned through experience over time and influenced heavily by local knowledge.

Some centers have, however, been experimenting with the development of scientific formulae to predict care needs at music festivals and other similar events. ${ }^{5}$ Other approaches have included the analysis of the interaction between psychosocial, environmental, and behavioral characteristics of events and patrons in order to better understand and plan the response at mass gatherings. ${ }^{28}$ It appears that such methods demonstrate some degree of promise, but their general applicability to all forms of music festival and mass gathering events has yet to be proven.

It is clear that despite the best efforts of organizers to plan the medical cover for music festivals, many of the resources are underutilized at events for a large proportion of the time. Future research is needed to identify ways of accurately predicting medical care requirements at music festivals to ensure that appropriate resources and skills are used optimally throughout events.

\section{Conclusion}

The provision of medical care at music events is an interesting and rewarding experience. One must bear in mind that a great deal of planning and preparation should be undertaken before medical resources are deployed to events. Much of the work encountered is likely to be relatively simple in nature but there is always the potential for the need for advanced care skills at the scene.

Good quality evidence from prospective studies with clear quality care measures are currently lacking. The evidence that is available indicates that the components of medical teams and the range of skills and resources available vary between events. Much of the planning for festivals is organized at a local level, sometimes with a degree of scientific rigor. Further work is required to identify methods to accurately predict workload at music festivals so that resources can be allocated appropriately.

The training required for personnel to be effective practitioners at music festivals needs further exploration. Coupled with this is the need for greater clarification on the degree of clinical governance and support for practitioners available within organizations that provide medical cover for events.

\section{Disclosure}

The authors report no conflicts of interest in this work.

\section{References}

1. Smith WP, Wessels V, Naicker D, Leuenberger E, Fuhri P, Wallis LA. Development of a mass-gathering medical resource matrix for a developing world scenario. Prehosp Disaster Med. 2010;25(6):547-552.

2. The event safety guide: A guide to health, safety and welfare at music and similar events. Crown copyright 1999. Available from: http://www. jonesphillips.com/includes/hsg195.pdf. Accessed August 13, 2012.

3. The Event Industry Forum [website]. Available from: http://www. eventsindustryforum.co.uk. Accessed August 12, 2012. eventsindustryforum.co.uk. Accessed on June 11, 2012.

4. Hewitt S, Jarrett L, Winter B. Emergency medicine at a large rock festival. J Accid Emerg Med. 1996;13:26-27.

5. Zeitz KM, Zeitz CJ, Arbon P. Forecasting medical work at massgathering events: predictive model versus retrospective review. Prehosp Disaster Med. 2005;20(3):164-168

6. Arbon P, Bridgewater FH, Smith C. Mass gathering medicine: a predictive model for patient presentation and transport rates. Prehosp Disaster Med. 2001;16(3):150-158.

7. Furst IM, Sándor GK. Analysis of a medical tent at the Toronto Caribana Parade. Prehosp Emerg Care. 2002;6(2):199-203.

8. Boyle MF, De Lorenzo RA, Garrison R. Physician integration into mass gathering medical care. The United States Air Show. Prehosp Disaster Med. 1993;8(2):165-168.

9. Olapade-Olaopa EO, Alonge TO, Amanor-Boadu SD, et al. On-site physicians at a major sporting event in Nigeria. Prehosp Disaster Med. 2006;21(1):40-44.

10. Feldman MJ, Lukins JL, Verbeek RP, MacDonald RD, Burgess RJ, Schwartz B. Half-a-million strong: the emergency medical services response to a single-day, mass-gathering event. Prehosp Disaster Med. 2004;19(4):287-296.

11. McDonald CC, Koenigsberg MD, Ward S. Medical control of mass gatherings: can paramedics perform without physicians on-site? Prehosp Disaster Med. 1993;8(4):327-331.

12. Yates KM, Hazell WC, Schweder L. Medical care at the Sweetwaters Music Festival. N Z Med J. 2001;114(1129):162-164.

13. Dalton AM, Sharma A, Touquet R. Notting Hill Carnival 1988. Arch Emerg Med. 1989;6(2):146-148.

14. Varon J, Fromm RE, Chanin K, Filbin M, Vutpakdi K. Critical illness at mass gatherings is uncommon. $J$ Emerg Med. 2003;25(4):409-413.

15. Dutch MJ, Senini LM, Taylor DJ. Mass gathering medicine: the Melbourne 2006 Commonwealth Games experience. Emerg Med Australas. 2008;20(3):228-233.

16. Gutman SJ, Lund A, Turris SA. Medical support for the 2009 World Police and Fire Games: a descriptive analysis of a large-scale participation event and its impact. Prehosp Disaster Med. 2011;26(1):33-39.

17. Martin-Gill C, Brady WJ, Barlotta K, et al. Hospital-based healthcare provider (nurse and physician) integration into an emergency medical servicesmanaged mass-gathering event. Am J Emerg Med. 2007;25(1):15-22. 
18. Meites E, Brown JF. Ambulance need at mass gatherings. Prehosp Disaster Med. 2010;25(6):511-514.

19. Hodgetts TJ, Cooke MW. The largest mass gathering. BMJ. 1999; 318(7189):957-958.

20. Zeitz KM, Schneider DP, Jarrett D, Zeitz CJ. Mass gathering events: retrospective analysis of patient presentations over seven years. Prehosp Disaster Med. 2002;17(3):147-150.

21. Woodall J, Watt K, Walker D, et al. Planning volunteer responses to low-volume mass gatherings: do event characteristics predict patient workload? Prehosp Disaster Med. 2010;25(5):442-448.

22. McQueen CP. Care of children at a large outdoor music festival in the United Kingdom. Prehosp Disaster Med. 2010;25(3):223-226.

23. Feldman MJ, Lukins JL, Verbeek PR, Burgess RJ, Schwartz B. Use of treat-and-release medical directives for paramedics at a mass gathering. Prehosp Emerg Care. 2005;9(2):213-217.

24. Baker WM, Simone BM, Niemann JT, Daly A. Special event medical care: the 1984 Los Angeles Summer Olympics experience. Ann Emerg Med. 1986;15(2):185-190.
25. Grange JT, Baumann GW, Vaezazizi R. On-site physicians reduce ambulance transports at mass gatherings. Prehosp Emerg Care. 2003;7(3):322-326.

26. Walker A, Brenchley J, Hughes N. Mobile radiography at a music festival. Emerg Med J. 2009;26(8):613.

27. Australian Emergency Manuals Series Part III, Emergency Management Practice, Volume 2 - Specific Issues Manual 2: Safe and Healthy Mass Gatherings, A Health, Medical and Safety Planning Manual for Public Events Commonwealth of Australia 1999. Available from http:// www.dh.sa.gov.au/pehs/publications/ema-mass-gatherings-manual.pdf. Accessed August 12, 2012.

28. Zeitz KM, Tan HM, Zeitz CJ. Crowd behavior at mass gatherings: A literature review. Prehospital Disast Med. 2009;24(1):32-38.

\section{Publish your work in this journal}

Open Access Emergency Medicine is an international, peer-reviewed, open access journal publishing original research, reports, editorials, reviews and commentaries on all aspects of emergency medicine. The manuscript management system is completely online and includes a very quick and fair peer-review system, which is all easy to use.

\section{Dovepress}

Visit http://www.dovepress.com/testimonials.php to read real quotes from published authors. 